\title{
Biodegradable Potential of Bacillus amyloliquefaciens and Bacillus safensis Using Low Density Polyethylene Thermoplastic (LDPE) Substrate
}

\author{
Muhammad Waqas ${ }^{1}$, Muhammad Haris ${ }^{1}$, Noreen Asim ${ }^{1}$, Hanif ul Islam ${ }^{1}$, Abdullah Abdullah ${ }^{2 *}$, Adil Khan ${ }^{3}$, \\ Huma Khattak ${ }^{3}$, Muhammad Waqas ${ }^{3}$, Sarfaraz Ali $^{3}$
}

\author{
${ }^{1}$ Institute of Biotechnology and Genetic Engineering, University of Agriculture, Peshawar, KPK, PAKISTAN \\ ${ }^{2}$ Department of Microbiology, Abdul Wali Khan University, Mardan, KPK, PAKISTAN \\ ${ }^{3}$ Department of Microbiology, Abasyn University, Peshawar, KPK, PAKISTAN \\ *Corresponding Author: abdul.9353chd@gmail.com
}

Citation: Waqas, M., Haris, M., Asim, N., Islam, H. ul, Abdullah, A., Khan, A., Khattak, H., Waqas, M. and Ali, S. (2021). Biodegradable Potential of Bacillus amyloliquefaciens and Bacillus safensis Using Low Density Polyethylene Thermoplastic (LDPE) Substrate. European Journal of Environment and Public Health, 5(2), em0069. https://doi.org/10.21601/ejeph/9370

\section{ARTICLE INFO}

Received: 16 Aug. 2020

Accepted: 11 Oct. 2020

\begin{abstract}
Increase of plastics accumulation in the environment cause ecological threats and has been one of the serious issue worldwide. In the current study, two bacterial isolated strains Bacillus safensis and Bacillus amyloliquefaciens were used for their plastic degradation capabilities. The biodegradation of low density polyethylene thermoplastic was assessed by weight reduction, Scanning electron microscopy (SEM) analysis and by culture media pH alteration. The results shows that Bacillus safensis was more efficient and degrade 18.6\% LDPE than Bacillus amyloliquefaciens that degrade 18\% of LDPE after incubation period of 30 days. Moreover, it was also noted that longer incubation periods results in higher biodegradation of low density polyethylene thermoplastic. It is concluded that the biodegrading ability of Bacillus safensis is more than Bacillus amyloliquefaciens as confirm from weight reduction of low density polyethylene thermoplastic.
\end{abstract}

Keywords: biodegradation, low density polyethylene, microbial degradation, Bacillus safensis, Bacillus amyloliquefaciens

\section{INTRODUCTION}

Land and water pollution caused by the extreme use of plastic is one of the major environmental problem worldwide. Plastic use has been incorporated into everyday life of human because of its low cost, various application, less weight and durability (Ghosh et al., 2013). Various type of plastics has been used continuously in our daily life such as polyethylene bags, polyvinyl chloride, and nylon etc (Smith., 1964). The demand for plastic production worldwide has been increased from 1.5 million to 245 million tons during 1950 to 2008 with a higher increase rate of $9 \%$ each year (S. Chanprateep et al., 2010).

However accumulation of huge amount of plastic waste is extremely dangerous to environment as it is nonbiodegradable in nature, and have known negative consequences for both human and animal health. The usage of polyethylene is increasing continuously at a risk rate of $12 \%$ each year worldwide (Roy et al., 2008). Packaging plastic (polythene bags) comprises about $10 \%$ of the total municipal waste created worldwide (Barnes et al., 2009). Small part of this polyethylene waste is reused while a large portion of the wastes are buried in the ground for the sake of degradation but is takes several years or may be not degrade (Lederberg, 2000; Moore, 2008). Wasted polyethylene bags is a serious threat to aquatic and terrestrial life, it could cause blockage in the gut of fowls, fishes, and other aquatic animals (Denuncio et al., 2011). 267 species in the marine ecosystem, including mammals, sea turtles, and seabirds are affected by the plastic pollution (Coe and Rogers, 1997). The death of terrestrial animals, such as bovine was reported because of eating of polythene bags in the field (Singh., 2005). The biodegradable polymers are manufacture to degrade it rapidly by microorganisms because of their capability to degrade most of the chemical compounds (Sadocco et al., 1997). Pseudomonas, Streptococcus, Staphylococcus, Micrococcus, and Moraxella, Aspergillus niger, Aspergillus glaucus, Actinomycetes sp. and Saccharomonospora genus has been identified for their potent biodegradable properties (Swift et al., 1997).

The current study focuses on the biodegradation capabilities of two bacterial isolates Bacillus safensis and 
Bacillus amyloliquefaciens against low-density polyethylene (LDPE).

\section{MATERIAL AND METHODS}

\section{Microorganisms}

The present study was intended to monitor biodegrading capability of two bacillus strains isolated and characterized previously at the Institute of Biotechnology and Genetic Engineering, The University of Agriculture Peshawar (IBGE) through conventional and molecular techniques.

\section{Pure Culture}

One hundred $\mathrm{mL}$ of nutrient Agar medium $(5 \mathrm{~g}$ yeast extract, $10 \mathrm{~g}$ of $\mathrm{NaCl}, 3 \mathrm{~g}$ of dextrose, $0.1 \mathrm{~g}$ of $\mathrm{NaH}_{2} \mathrm{PO}_{4}, 0.5 \mathrm{~g}$ of $\mathrm{KH}_{2} \mathrm{PO}_{4}$, and15g of agar with adjusted $\mathrm{pH}$ of $7.4 \pm 0.2$ ) was prepared and autoclaved by following standard procedures. Next day streaking was done under sterile condition at room temperature.

\section{Inoculum Preparation}

One hundred $\mathrm{mL}$ of nutrient broth medium composed of g/L: (yeast extract $5 \mathrm{~g}, \mathrm{NaCl} 10 \mathrm{~g}$, dextrose $3 \mathrm{~g}, \mathrm{NaH}_{2} \mathrm{PO}_{4} 0.1 \mathrm{~g}$, $\mathrm{KH}_{2} \mathrm{PO}_{4} 0.5 \mathrm{~g}$ with $\mathrm{pH}$ of $7.4^{ \pm} 0.2$ ) was prepared and incubated overnight at $30^{\circ} \mathrm{C}$.

\section{Pre-treatment for LDPE}

Low-density polyethylene (LDPE) was cut into small fragments, washed with distilled water and sterilized in ethanol for $15 \mathrm{~min}$. Residual ethanol was removed by further washing, following by the addition of $0.1 \%$ mercuric chloride and washing continuously.

\section{Biodegradation Studies}

Bacteria were isolated and recognized as plastic-degrading bacillus strains which were developed and grown in supplement media ( $5 \mathrm{~g}$ peptone, $5 \mathrm{~g} \mathrm{NaCl}, 1.5 \mathrm{~g}$ yeast extract, and $1.5 \mathrm{~g}$ HM peptone with the adjusted $\mathrm{pH}$ of 7.4). The media was autoclaved at $121^{\circ} \mathrm{C}$ for 20 minutes. About $200 \mathrm{ml}$ media was added into $250 \mathrm{ml}$ sterilized Erlenmeyer flask. $1 \mathrm{ml}$ of overnight inocula from both strains with $1 \mathrm{~g}$ of plastic was supplemented into broth.

\section{Evaluation of Degradation}

The plastic pieces were removed from the bacterial culture at day 10, 20, and 30. The collected pieces were rinsed with distilled water to remove any attach microbe to its surface. The pieces were then air dried in oven at $60^{\circ} \mathrm{C}$ and weighed to determine weight loss. The same procedure was done for all other samples.

\section{pH Evaluation}

Estimation of $\mathrm{pH}$ change was studied to confirm any metabolic activity of the microbial isolates in supplemented medium. If the $\mathrm{pH}$ increased that show metabolism microbial cells incredibly support that the strains are dynamic and provide a proof of degradation. The $\mathrm{pH}$ of each bacterial culture was calculated at an interval of 10, 20 and 30 days respectively during the study.

\section{Optical Density}

Optical density was calculated after 5, 10, 20, and 30 days using UV/VIS Spectrophotometer at $610 \mathrm{~nm}$ in order to ensure growth of the bacteria.

\section{Final Weight Determination}

Final weight of polythene bag was determined to check extent of degradation. The plastic pieces were removed after 10,20 and 30 days of incubation and were sterilized, dried until removal of moisture and weighed for final weight. The extent of degradation of LDPE pieces by Bacillus safensis and Bacillus amyloliquefaciens was determined by calculating the percentage of weight loss of plastic pieces which was calculated by the given formula:

Percentage of weight loss = Initial weight - Final_weight / Initial weight x 100

\section{RESULTS}

\section{Biodegradation Studies}

After incubation process of 10, 20 and 30 days, the degrading ability of the two bacterial strains Bacillus safensis and Bacillus amyloliquefaciens were evaluated and were interpret using different parameters.

\section{Weight Decrease}

Weight loss is the primary mean for the determination of polymer degradation. Microorganisms that grow on polymer cause weight loss of LDPE. The changes occurred due to microbial activity were qualitatively measured by the weight loss of the LDPE after inoculation with Bacillus safensis ( $\mathrm{pwg}^{-7}$ ) and Bacillus amyloliquefaciens $\left(\mathrm{C}_{2} \mathrm{Ssk}^{-8}\right)$. The weight loss was monitored on regular interval of 10, 20 and 30 days. The weight reduction of LDPE was $9.9 \%, 16.9 \%$ and $18.6 \%$ after 30 days of incubation with Bacillus safensis and 6\%, 13.4 and 18\% with Bacillus amyloliquefaciens respectively. The weight loss results are illustrated in Figure 1. Among the two isolates in the experiment, Bacillus safensis was found to be more efficient than Bacillus amyloliquefaciens in degradation of polythene bag after 30 days of incubation that was recorded about $18.6 \%$.

pH

The deviation in $\mathrm{pH}$ of both bacterial culture before and after the biodegradation process are illustrated in Figure 2. Bacterial isolates, Bacillus safensis and Bacillus amyloliquefaciens demonstrated the generation of compounds and metabolites with the indication of $\mathrm{pH}$ change supporting the metabolic activity of strains on the LDPE and its degradation.

\section{Change in Optical Density}

Changes in optical density of medium within 30 days incubation treatment are illustrated in Figure 3. Optical density was increased from day first to day 30 . The highest optical density was observed for Bacillus safensis after 30 days of treatment. 


\section{WEIGHT REDUCTION}

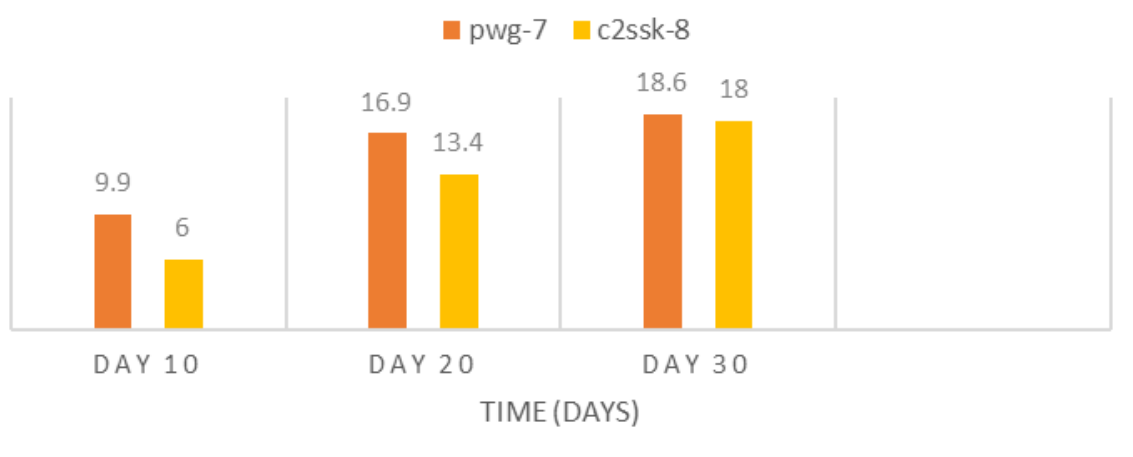

Figure 1. Weight Reduction of LDPE by using Bacillus safensis and Bacillus amyloliquefaciens

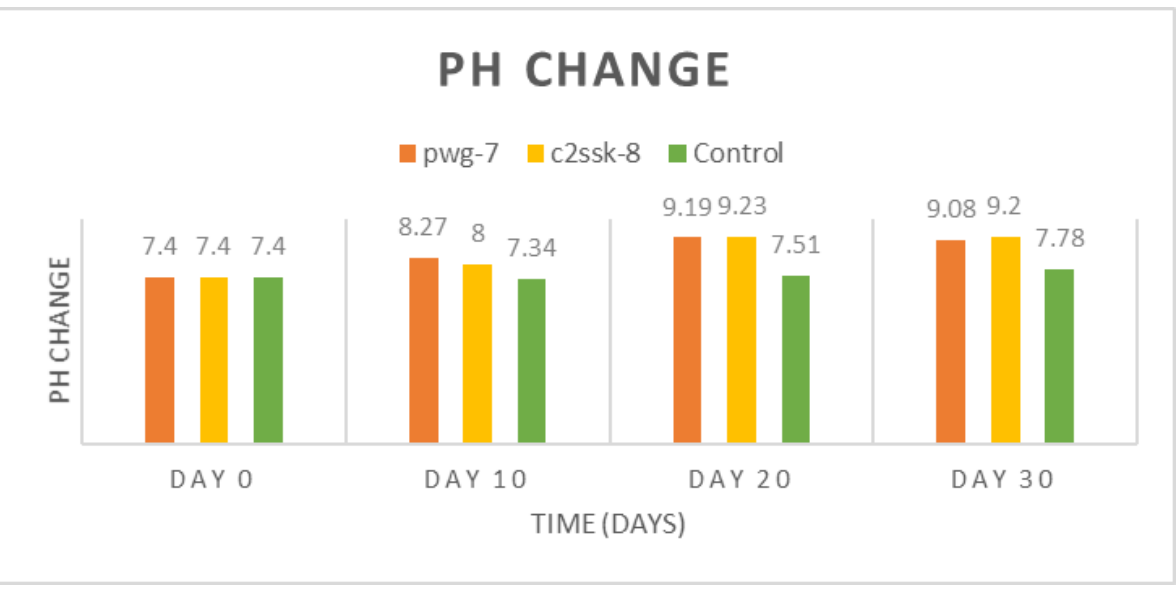

Figure 2. Changes of $\mathrm{pH}$ value due to microbial activity during biodegradation

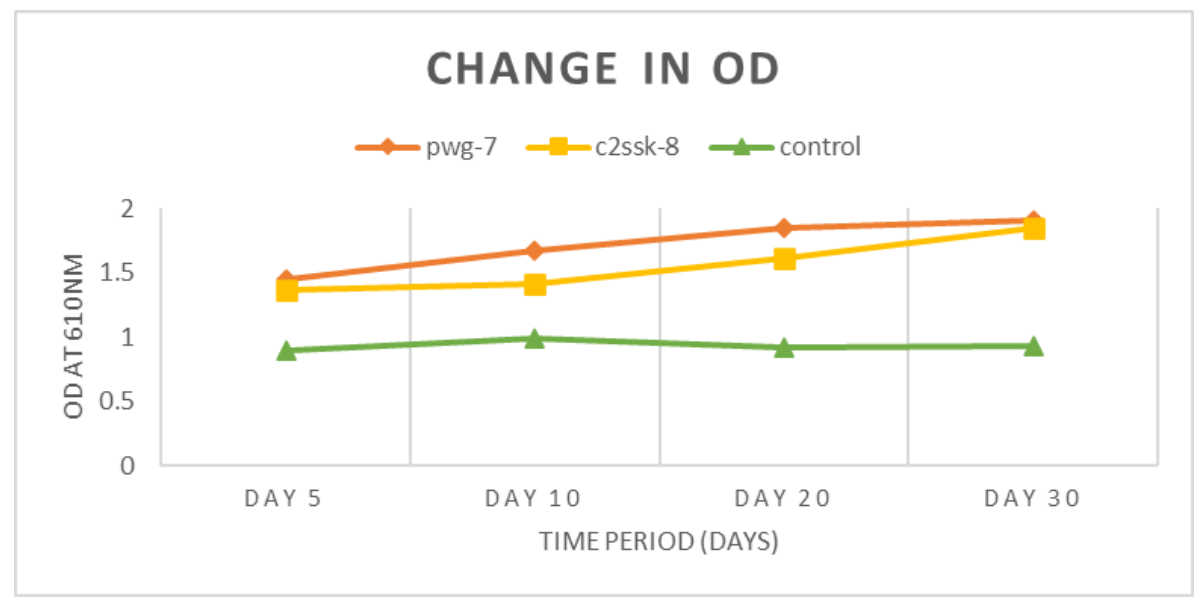

Figure 3. Changes in optical density of the culture medium during the process

\section{DISCUSSION}

The biodegradation capability of Bacillus amyloliquefaciens has been reported many time (Das Kumar et al., 2015). Bacillus safensis isolated in this study had not been testified before and is a novel bacteria that can degrade LDPE. Biodegradation of organic compounds through microbes require oxygen, nutrients and physio-chemical conditions like temperature and $\mathrm{pH}$ (Fred, 2001). We provide these control condition to our bacterial culture that have the capability to degrade carbon compounds by utilizing them as sole source of energy and carbon by using its own enzymatic system (AMSA, 2004; Dagly, 1984). In this study two of the bacterial strains were used Bacillus safensis and Bacillus amyloliquefaciens. Bacillus safensis showed a high degradation activity against LDPE as compare to Bacillus amyloliquefaciens. During biodegradation bacteria used plastic as sole source of carbon and energy which result in weight reduction of the LDPE. Results showed that the weight reduction was $18.6 \%$ for Bacillus safensis and $18 \%$ for 
Bacillus amyloliquefaciens after incubation while there was no changed occurred in untreated LDPE.

$\mathrm{pH}$ is an essential aspect for the survival and action of microbes that guarantee the production of enzyme which results in beginning of degradation (Xu et al., 2011). These bacterial isolates secret some extracellular and intracellular enzyme in the suspension media that responsible for degrading ability. Most favorable $\mathrm{pH}$ for the biodegradation process of hydrocarbons is 6-9 (Mentzer and Ebere, 1996). The results revealed variation in the $\mathrm{pH}$ of culture media through the 30 days of incubation period with Bacillus safensis and Bacillus amyloliquefaciens. The $\mathrm{pH}$ of the aqueous media continuously increased toward alkalinity that might be considered for degradation.

\section{CONCLUSION}

Both strains Bacillus safensis and Bacillus amyloliquefaciens has the capability to degrade low density polyethylene (LDPE). It was found that the degrading ability of Bacillus safensis is more than Bacillus amyloliquefaciens as confirm from weight reduction. As plastic is the major threat to human health and environment, we can easily eliminate plastics by using these strains.

\section{ACKNOWLEDGEMENTS}

We are grateful to Institute of Biotechnology and Genetic Engineering, University of Agriculture, Peshawar, KPK, Pakistan for providing research facilities.

\section{REFERENCES}

AMSA. (2004). Management and disposal of oil spill debris. Land farming of oil and oily Debris: Marine environmental protection. AMSAs Role in Maritime Environmental Issues, Australian Maritime Safety Authority., 1-24.

Barnes, D. K. A., Galgani, F., Thompson, R. C. and Barlaz, M. (2009). Accumulation biodegradation of plastics. J. Environ Sci Pollut Res., 20, 4339-4355.

Chanprateep, S. (2010). Current trends in biodegradable polyhydroxyalkanoates. J Biosci Bioeng, 110, 621-632. https://doi.org/10.1016/j.jbiosc.2010.07.014

Coe, J. M. and Rogers, D. B. (1997). Marine Debris: sources, impacts, and solutions. Science, Springer, New York. J. Natur Scie., 3(11), 49-66. https://doi.org/10.1017/ s0025315400036341

Dagly, S. (1984). Introduction in Microbial Degradation of Organic Compounds. Marcel Dekker Inc. New York, USA. J. Natur scie., 5(7), 80-94.
Das, M. P. and Kumar, S. (2013). Influence of cell surface hydrophobicity in colonization and biofilm formation on LDPE biodegradation. Int J Pharm Pharm Sci, 5, 690-694.

Denuncio, P., Bastida, R., Dassis, M., Giardino, G. and Gerpe, M. (2011). Plastic ingestion in Franciscana dolphins, Pontoporia blainvillei (Gervais and d Orbigny, 1844), from Argentina. J. Mar Pollut Bull., 3, 25-30. https://doi.org/10.1016/j.marpolbul.2011.05.003

Fred, A. A. (2001). Analyst bacteria for crude oil and some of its derivatives from the soil of southern Iraq. M.S. Thesis, University of Basra, Basra. J. scie inter., 2(10), 20-25.

Ghosh, S. K., Pal, S. and Ray, S. (2013). Study of microbes having potentiality for biodegradation of plastics. Environ Sci Pollut Res, 20, 4339-4355. https://doi.org/10.1007/s11356-013-1706-x

Lederberg, J. (2000). Encyclopedia of microbiology. D-K. Academic Press, New York.

Mentzer, E. and Ebere, D. (1996). Remediation of hydrocarbon contaminated sites. Proceedings of the 8th Biennial International Seminar on the Petroleum Industry and Nigerian Environment, November 17-21, 1996, Port Harcourt, Nigeria.

Moore, C. J. (2008). Synthetic polymers in the marine environment: A rapidly increasing, long-term threat. $J$. Environ. Res., 108, 131-139. https://doi.org/10.1016/ j.envres.2008.07.025

Roy, P. K., Surekha, P., Tulsi, E., Deshmukh, C. and Rajagopal, C. (2008). Degradation of abiotically aged LDPE films containing pro-oxidant by bacterial consortium. J. Polym. Degrad. Stab., 93, 1917-1922. https://doi.org/10.1016/ j.polymdegradstab.2008.07.016

Sadocco, P., Nocerino, S., Dubini-Paglia, E., Seves, A. and Elegir, G. (1997). Characterization of a poly (3hydroxybutyrate) depolymerase from polymers (pp. 473-511). Amsterdam: Hardwood Academic.

Singh, B. (2005). Harmful effect of plastic in animals. Indian Cow., J. IIOAB, 2, 10-18.

Smith, W. M. (1964). Manufacture of plastic, Vol. 1. Technology and Engineering, Reinhold Pub. J. Corp, USA. Soc. B Biol. Sci., 364, 1985-1998.

Swift, G. (1997). Non-medical biodegradable polymers: environmentally degradable polymers. In: Handbook of biodegradable test system. J. Int Biodeter. Biodeg., 37, 8592. https://doi.org/10.1201/9781420049367.ch23

Xu. L., Crawford, K., Gorman, C. B. (2011). Effects of temperature and $\mathrm{pH}$ on the degradation of poly(lactic acid) brushes. J. Macromolecules, 44, 4777-4782. https://doi.org/10.1021/ma2000948 